\title{
Genetic control of Eucalyptus globulus seed germination
}

\author{
Kieren D. Rix • Alistair J. Gracie • Bradley M. Potts • \\ Philip H. Brown • Peter L. Gore
}

Received: 5 May 2014 / Accepted: 26 December 2014 /Published online: 22 January 2015

(C) INRA and Springer-Verlag France 2015

\begin{abstract}
- Key message The maternal genotype has a significant effect on most germination traits of Eucalyptus globulus seeds. These differences can be partly explained by genetic-based differences amongst races, including differences in sensitivity to high temperatures which may be of adaptive significance.

- Context Slow and uneven germination of Eucalyptus globulus seeds in commercial nurseries can be a problem which has been linked with periods of high temperature.

- Aims This study aimed to determine whether maternal genotype affects the germination of E. globulus seeds.
\end{abstract}

\section{Handling Editor: Bruno Fady}

Contribution of the co-authors Alistair J. Gracie: Primary supervisor of the $\mathrm{PhD}$ project this work was included in.

Bradley M. Potts: Supervisor of the $\mathrm{PhD}$ project this work was included in. Phillip H. Brown: Supervisor of the $\mathrm{PhD}$ project this work was included in. Peter L. Gore: Initiated the project and provided guidance and support for the $\mathrm{PhD}$ project from which this work was derived.

Note: Microsoft Excel was used to create the Figures contained in the manuscript.

K. D. Rix $(\bowtie) \cdot$ A. J. Gracie

Tasmanian Institute of Agriculture, University of Tasmania,

Hobart, Tasmania 7001, Australia

e-mail: kdrix@utas.edu.au

\section{B. M. Potts}

School of Biological Sciences and National Centre for Future Forest Industries, University of Tasmania, Private Bag 55,

Hobart, Tasmania 7001, Australia

\section{P. H. Brown}

Centre for Plant and Water Science, Central Queensland University, BundabergLocked Bag 3333Queensland 4670, Australia

P. L. Gore

seedEnergy Pty Ltd, 2 Derwent Avenue, Margate, Tasmania 7054, Australia
- Methods By sampling seeds over two seasons from multiple randomised ramets (trees) of maternal genotypes from three races of E. globulus growing in a seed orchard, the extent of genetic control of seed germination responses was assessed at different germination temperatures.

- Results Maternal genotype had a significant effect on most germination traits but a differential response to temperature was more evident for germination proportion than rate traits. Maternal races differed in their rate of seedling development regardless of temperature, but differences in the germination proportion were only detected at high temperatures.

- Conclusion The present study highlights the potential adaptive significance of the germination response and the need for seed lot-specific germination testing as both genetics and maternal environment vary.

Keywords Eucalyptus globulus · Seed germination - Genetic regulation

\section{Introduction}

The maternal parent may influence the phenotype of its offspring through direct or indirect genetic or environmental effects (Roach and Wulff 1987). Genetic effects may be due to the contributions to the nuclear genotype of the embryo and through specific maternal effects. Maternal effects are signalled when the offspring performance exceeds the $50 \%$ expectation from Mendelian inheritance (Lacey 1998; Galloway et al. 2009). They may arise from cytoplasmic genetic, endosperm nuclear and maternal phenotypic effects (Roach and Wulff 1987). Maternal phenotypic effects result from the environment or genotype of the maternal parent and are probably the least well understood class of maternal effects. These effects include epigenetic (Besnard et al. 2008) as well as biotic 
and abiotic environmental effects (Roach and Wulff 1987; Mazer and Gorchov 1996; Lacey 1998).

Maternal effects have been widely documented in plants and can affect offspring vigour and fitness (Roach and Wulff 1987; Byers et al. 1997; Donohue 2009; Galloway et al. 2009). Most studies of maternal effects in plants have focused on characters expressed early in the life cycle (e.g. seed size, seed mass, dormancy and germination (Galloway 2001; Bischoff and Muller-Scharer 2010). Maternal effects can influence the sensitivity of seeds to environmental conditions (Roach and Wulff 1987). For example, the sensitivity of lettuce seeds to high temperature stress during germination was partly related to maternal environment (Sung et al. 1998). Although maternal effects are most common in the early stages of the life cycle (Roach and Wulff 1987), they can persist into adulthood (Galloway et al. 2009) and even transgress generations (Byers et al. 1997; Besnard et al. 2008). These effects may result from direct or indirect causes. For example, direct maternal effects on traits, such as seed size and germination, are common and because these traits can greatly affect early seedling growth (Roach and Wulff 1987; Galloway et al. 2009), the maternal effects may persist into later stages of the life cycle.

Studies of direct and indirect maternal effects in plants have focused on short-lived annuals (Byers et al. 1997). There are few such studies in long-lived forest trees, but an example include the demonstration of "seed after-effects" whereby the environment experienced by parents and developing seeds in a tree seed orchard may affect the expression of phenotypic variation in the subsequent deployment population (Andersson 1994; Stoehr et al. 1998). Few studies allow the separation of maternal embryonic nuclear and maternal effects (Rasanen and Kruuk 2007; Monty et al. 2009; Bischoff and Muller-Scharer 2010), particularly in the case of forest trees (Besnard et al. 2008). This is partly because many studies confound genetic effects with maternal environment, by not having replicated maternal genotypes growing in common environment trials (Rasanen and Kruuk 2007; Monty et al. 2009). The present study focuses on the role that maternal genotype plays in the seed germination responses of the Australian forest tree, Eucalyptus globulus Labill.

E. globulus is one of the few eucalypt species in which maternal and seed after-effects have been studied. López et al. (2003) showed that seed mass exhibited a significant maternal effect, increasing seed germinative capacity but not germination rate. This study could not, however, differentiate maternal genetic from maternal environment effects on germination, because seeds were harvested from trees in native stand localities and therefore maternal genetic effects were confounded with maternal environment effects. High germination temperatures (above $30^{\circ} \mathrm{C}$ ) have been shown to deleteriously affect the germination response of E. globulus seed
(López et al. 2000; Rix et al. 2011). Outdoor temperatures in some Australian nurseries can exceed the optimum of $25^{\circ} \mathrm{C}$ (ISTA 2012) and during summer temperatures can reach as high as $40^{\circ} \mathrm{C}$. Rix et al. (2011) showed that temperatures above $30^{\circ} \mathrm{C}$ generally delayed commencement of germination, reduced total germination percentage, caused a high proportion of seed death and suppressed the development of normal seedlings in commercial E. globulus seed lots. Thus, high temperature exposure in nurseries can impact on the number and uniformity of seedlings, leading to significant losses.

Differences amongst commercial seed lots in high temperature sensitivity were noted by Rix et al. (2011), but the experimental design did not allow determination of whether these differences were due to genetic, environmental or treatment effects. A subsequent study using reciprocal matings of E. globulus undertaken in the same seed orchard with replication of the female genotype showed that there are paternal and maternal effects on the germination response (Rix et al. 2012b). This result argues for at least some influence of the nuclear genotype, but the response to high temperature stress was shown to be more influenced by the maternal parent (Rix et al. 2012b). The four genotypes studied were from one (Western Otways) of thirteen native races of E. globulus, which are genetically differentiated in many functional traits (Dutkowski and Potts 1999; Stackpole et al. 2011), including drought susceptibility (Dutkowski and Potts 2012).

In the present study, we use a broader sample of genotypes and aimed to determine the following: (i) whether maternal genetic variation both within and between races affects the germination of E. globulus seeds, (ii) whether these effects are differentially expressed under high temperature stress and (iii) the stability of maternal genetic influences on germination across different seed crops.

\section{Materials and methods}

\subsection{Study sites and germplasm}

This study was based on replicated E. globulus genotypes growing in a seed orchard at Cambridge in south-eastern Tasmania ( $42^{\circ} 48^{\prime} 27.23^{\prime \prime} \mathrm{S}, 147^{\circ} 25^{\prime} 58.48^{\prime \prime} \mathrm{E}$ ); see (Suitor et al. 2008; Jones et al. 2011). The genotypes were base population selections from the Southern Tree Breeding Association (STBA) National E. globulus Breeding Program and were from open-pollinated progeny derived from wild maternal trees growing in three native races-Furneaux, Western Otways and Strzelecki Ranges (Jones et al. 2006; Potts et al. 2008), hereafter referred to as Furneaux, Otways and Strzelecki. For each race, climatic variables at the home-site were predicted from ANUCLIM version 6.1 (Xu and Hutchinson 2010) based on the averages of the predictions for all trees sampled in the original native population 
collection from the relevant races (Dutkowski and Potts 1999). The number of genotypes sampled per race varied from six for Furneaux, seven for Otways and three (2008-9) to four (2007-8) for the Strzelecki race. Genotypes were arranged in replicated line plots distributed at random throughout the orchard. For each genotype, generally four ramets were sampled, one from each line plot in virtually all cases, thus allowing genotype effects to be tested.

Seed lots were collected from trees in the orchard in the 2007/08 flowering season and a year later in the 2008/09 flowering season. For the 2007/08 sampling, seed capsules were collected 13 months from when each genotype first flowered (flowering data from Jones et al. (2011)). In 2008/09, the genotypes were harvested to coincide with commercial harvesting of the orchard, which meant the time from first flowering ranged from 10 to 13 months. In the 2007/08 season, seed lots derived from two trees out of 52 were from mass-supplementary pollination (MSP) (Patterson et al. 2004) and the remainder were derived from openpollination (OP). In the 2008/09 season at Cambridge, seeds from 15 trees out of 45 were from MSP and the remainder was derived from OP.

\subsection{Seed extraction and germination}

Seed extraction as well as germination procedures and assessment are detailed in (Rix et al. 2012a; 2012b). In brief, the number of seeds per capsule and weight of 100 seeds were recorded for the sample from each ramet. All seeds were germinated within 8 to 17 months from harvest. Seeds were germinated in controlled environment incubators set at 25 (optimal), 32 and $37{ }^{\circ} \mathrm{C}$ (high temperatures) under continuous white fluorescent light. In most cases, 50 seeds (average 49.8) from each tree (seed lot) were uniformly spaced on filter paper within germination incubators and this comprised the experimental unit. One such replicate of each seed lot was germinated at each temperature. The allocation of seed lots was randomised within each temperature. In addition, three to six replicates of 50 seeds each of a commercial openpollinated seed lot (Glob 185-see Rix et al. (2011)) were germinated at each temperature during each germination run as a control to confirm consistency of germination conditions between runs.

For the 2007/08 season, seed germination tests were undertaken in two runs (runs 1 and 2). Half of the replicates of each genotype were germinated in the first run and the other half in the second run. This was done because there was insufficient space in the germination incubators to complete the experiment in a single run. For the 2008/09 season, seeds from Cambridge (run 3) were germinated in a single run. All data was adjusted using the grand mean of the control seed lot for each temperature to account for any differences in test conditions between runs (Rix et al. 2012a).
Assessments were conducted regularly, with scoring daily or every second day during periods of peak germination and every 3 to 4 days when germination rate was low. The duration of the experiments was 21 or 22 days. At each assessment, a seed was recorded as germinated when there was visible protrusion of the radicle through the seed coat. Seedlings with a radicle at least one third the length of the seedling, a hypocotyl and two expanded cotyledons were classified as normal, in accordance with ISTA guidelines (Bekendam and Grob 1993; ISTA 2012) and removed. On the final day of scoring, remaining seeds in Runs 2 and 3 were squashed and scored as fresh ungerminated (embryo remains firm and apparently viable and healthy) or dead (endosperm is soft and showing signs of decomposition) in accordance with ISTA (2012). Remaining seedlings on the final day of scoring were scored as normal or abnormal to differentiate those unlikely to survive in the nursery. Abnormalities included stunted radicles, failure of radicles to emerge but emergence of cotyledons and failure of seedlings to shed seed coats, in accordance with ISTA guidelines for seedling evaluation (Bekendam and Grob 1993; ISTA 2006).

\subsection{Statistical analysis}

The data were summarised into four response traits for each experimental unit of 50 seeds, two measuring proportions and two measuring rates as detailed in Rix et al. (2012a; 2012b). The proportional data included germination proportion (the proportion of seeds sown that germinated-Germ/Sown) and the proportion of germinated seeds that developed into normal seedlings (Normals/Germ). The rate data included the time taken to reach $50 \%$ (T50) of the maximum germination attained (T50Germ) and the T50 for maximum normal seedlings developed (T50Normals). The T50 values were estimated by fitting a logistic function to the cumulative curves for germination or seedling development for each experimental unit of 50 seeds. This was done using the Marquardt's iterative non-linear procedure (PROC NLIN) of SAS version 9.1 (SAS Institute Inc 2003). The proportion traits were chosen to distinguish between the number of seeds which germinated and the number of those germinated seeds which developed into normal seedlings. This subsequent development is of critical importance from a nursery perspective as well as reflecting a different early life stage. The rate traits were chosen because variation in rate of germination and seedling development can result in non-uniformity of seedlings later on. This is very important in a nursery context where seedlings are produced to exacting specifications.

The data were analysed in several stages by fitting generalised linear mixed models with PROC GLIMMIX of SAS Version 9.1 (SAS Institute Inc 2003). For the quantitative rate traits, a log transformation was used to optimise normality and homogeneity of residuals, a normal distribution was assumed 
and the models fitted using restricted maximum likelihood. The events/trials syntax was used for binary data from each experimental unit (in virtually all cases trials $=50$ ), and model fitting undertaken using maximum likelihood estimation. A binomial distribution was assumed with a logit link function, and least-square means (LSMEANS) estimated on the unlinked scale using the ILINK option. Fixed effects and covariates were tested using Type III tests and the default containment method for estimation of degrees of freedom. The SLICE option was used to partition interactions and obtain Type III tests of simple effects (e.g. temperature within each level of race or vice versa). Variance components for random terms were tested from zero using a likelihood ratio test.

\subsection{Between genotypes within seasons}

The data from the germination trials were initially analysed for each season separately, fitting a race model where temperature, race and the two-way interaction were treated as fixed effects and genotype within race and its two-way interaction with temperature and tree within genotype treated as random effects. Genotype within race was used to test the fixed race effect. The temperature by genotype within race interaction was used to test the fixed temperature and race by temperature effects. The other fixed effects were tested against the residual error term. A model which treated temperature, genotype and their two-way interaction as fixed effects (genotype model) was also fitted to estimate genotype least-square means. Tree within genotype was treated as a random effect and used to test the fixed genotype effect. The temperature and interaction terms were tested against the residual error. To test whether number of seeds per capsule (covariate), seed weight (measured as the weight $[\mathrm{g}]$ of 100 seeds; covariate) or pollination type (OP or MSP; factor) affected the germination response, these terms were included separately in these genotype and race models.

\subsection{Stability of genotype effects across seasons}

The analysis of the differences in genotype performance across the 2007/08 and 2008/09 sampling seasons was restricted to data from 14 genotypes where two or more ramets were sampled in both seasons and in most cases the same ramet was sampled in both seasons. For the four germination traits, the fixed effects of season, genotype (ignoring race), temperature and their two- and threeway interactions were fitted. Tree within genotype and its two-way interactions with temperature and season were treated as random effects, and used to test the fixed genotype and interaction effects. Other fixed effects were tested using the residual error.

\subsection{Seed set and seed size}

The effects of genotype and season on seed set and seed weight were tested using the same 14 genotypes as above. The fixed effects of genotype, season and their interaction on the number of seeds obtained per capsule and seed weight were tested using a generalised linear mixed model and the residual as the error term. The race effects on the number of seeds obtained per capsule and seed weight were also tested with race, season and their interaction as fixed effects. In this case, the genotype within race and its interaction with season were fitted as random effects and used to test terms involving race.

\section{Results}

\subsection{Genetic effects on seed germination within season}

Test temperature was the main factor affecting both the proportion and rate of seed germination and normal seedling development (Table 1). However, tree genotype also affected both the proportion and rate of seed germination and the rate of normal seedling development. Genotype differences in the proportion traits were strongly temperature dependent (Table 1). The germination proportion of seed lots from some genotypes were insensitive to changing test temperature (e.g. Germ/Sown in 2007/08 - genotype 4928, $P=0.088$; genotype 5474, $P=$ 0.531 ; genotype $5856, P=0.1961$ ), whereas temperature affected $(P<0.05)$ all other genotypes due to the highest temperature significantly reducing germination proportion (Fig. 1). The deleterious effect of $37^{\circ} \mathrm{C}$ on the proportion of germinated seeds that developed into normal seedlings was evident for all genotypes, although the magnitude of the effect differed. These deleterious effects were particularly evident in the atypical high temperature sensitivity of Furneaux genotype 6071 for both germination proportion (Fig. 1) and proportion of germinated seeds that developed into normal seedlings.

There were differences between races in the germination proportion (Germ/Sown), but these were temperature dependent. The significant race $\times$ temperature interaction was mainly due to seeds from the Strzelecki race being less adversely affected by germination temperature (Germ/Sown - 2007/08 $\left.F_{2,28}=3.7, P=0.037 ; 2008 / 09 F_{2,26}=2.8, P=0.079\right)$ than those from the Otways $\left(2007 / 08 F_{2,28}=11.2, P<0.001 ; 2008 / 09\right.$ $\left.F_{2,26}=8.3, P=0.002\right)$ and particularly Furneaux $(2007 / 8$ $\left.F_{2,28}=24.5, P<0.001 ; 2008 / 9 \quad F_{2,26}=15.5, P<0.001\right)$ (Fig. 2). None of the fixed effects explained variation in the proportion of the seeds sown that were scored as dead at the end of the experiment, rather reduced germination at high temperatures was directly due to increased proportions of the fresh ungerminated seeds (data not shown). There was similarly no significant effect of either temperature, race or their 
Table 1 Effect of genotype and temperature on four germination traits

\begin{tabular}{|c|c|c|c|c|c|c|c|c|c|c|}
\hline \multirow[b]{3}{*}{ Fixed effects } & \multirow[b]{3}{*}{ Num d.f. } & \multirow[b]{3}{*}{ Den d.f. } & \multicolumn{4}{|c|}{ Proportion } & \multicolumn{4}{|l|}{ Rate } \\
\hline & & & \multicolumn{2}{|c|}{ Germ/Sown } & \multicolumn{2}{|c|}{ Normals/Germ } & \multicolumn{2}{|c|}{ T50Germ } & \multicolumn{2}{|c|}{ T50Normals } \\
\hline & & & $F$ & $P$ & $F$ & $P$ & $F$ & $P$ & $F$ & $P$ \\
\hline \multicolumn{11}{|l|}{ Between races } \\
\hline \multicolumn{11}{|l|}{ Cambridge 2007/08 } \\
\hline Temperature & 2 & 28 & 30.0 & $<0.001$ & 78.8 & $<0.001$ & 67.9 & $<0.001$ & 81.2 & $<0.0001$ \\
\hline Race & 2 & 14 & 1.5 & 0.268 & 2.4 & 0.124 & 2.9 & 0.088 & 4.4 & 0.034 \\
\hline Race $\times$ temperature & 4 & 28 & 2.9 & 0.041 & 1.1 & 0.394 & 2.3 & 0.082 & 3.2 & 0.028 \\
\hline \multicolumn{11}{|l|}{ Cambridge 2008/09 } \\
\hline Temperature & 2 & 26 & 15.6 & $<0.001$ & 67.0 & $<0.001$ & 98.9 & $<0.001$ & 137.8 & $<0.001$ \\
\hline Race & 2 & 13 & 1.9 & 0.183 & 4.3 & 0.015 & 3.6 & 0.059 & 3.8 & 0.051 \\
\hline Race $\times$ temperature & 4 & 26 & 2.1 & 0.113 & 1.2 & 0.182 & 2.1 & 0.108 & 1.9 & 0.136 \\
\hline \multicolumn{11}{|l|}{ Within races (random effects) } \\
\hline Cambridge 2007/08 & & & ChiSq & $P$ & ChiSq & $\mathrm{P}$ & ChiSq & $\mathrm{P}$ & ChiSq & $\mathrm{P}$ \\
\hline Genotype (race) & 14 & 35 & 2.3 & 0.064 & 0.0 & 1.000 & 21.1 & $<0.001$ & 14.1 & $<0.001$ \\
\hline Temperature $\times$ genotype (race) & 28 & $56-57$ & 93.9 & $<0.001$ & 42.4 & $<0.001$ & 0.4 & 0.258 & 0.8 & 0.192 \\
\hline \multicolumn{11}{|l|}{ Cambridge 2008/09 } \\
\hline Genotype (race) & 13 & 29 & 10.5 & $<0.001$ & 0.1 & 1.000 & 33.8 & $<0.001$ & 28.0 & $<0.001$ \\
\hline Temperature $\times$ genotype (race) & 26 & $56-57$ & 37.1 & $<0.001$ & 40.5 & $<0.001$ & 0.1 & 0.365 & 0.0 & 1.000 \\
\hline
\end{tabular}

Analyses were undertaken on seeds collected from E. globulus genotypes growing in a grafted seed orchard at Cambridge, Tasmania. Seeds were from capsules collected in 2007/08 and 2008/09 from the previous flowering year. Genetic effects and their temperature interactions are shown at the race and genotype within race levels. The response traits are the germination proportion (Germ/Sown), the proportion of germinated seeds that developed into normal seedlings (Normals/Germ), germination rate (T50Germ) and the rate of normal seedling development (T50Normals)

$F$ Walds $F$ value, $P$ probability, Num d.f. numerator degrees of freedom, Den d.f. denominator degrees of freedom

interaction on the proportion of the ungerminated seed which were scored as dead, which ranged from 0.00 to 0.26 across temperatures in $2007 / 08$ and from 0.31 to 0.43 in 2008/09.

Increasing temperature significantly reduced the proportion of germinated seeds that developed into normal seedlings
(Norms/Germ; Table 1), from a mean of 0.96 or $0.95\left(25^{\circ} \mathrm{C}\right)$ to 0.62 or $0.61\left(37^{\circ} \mathrm{C}\right)$ in $2007 / 09$ and $2008 / 09$, respectively. The overall proportion of germinated seeds that developed into normal seedlings was highest in Strzelecki seed lots (Strzelecki $>$ Furneaux $>$ Otways in both seasons) and this trend

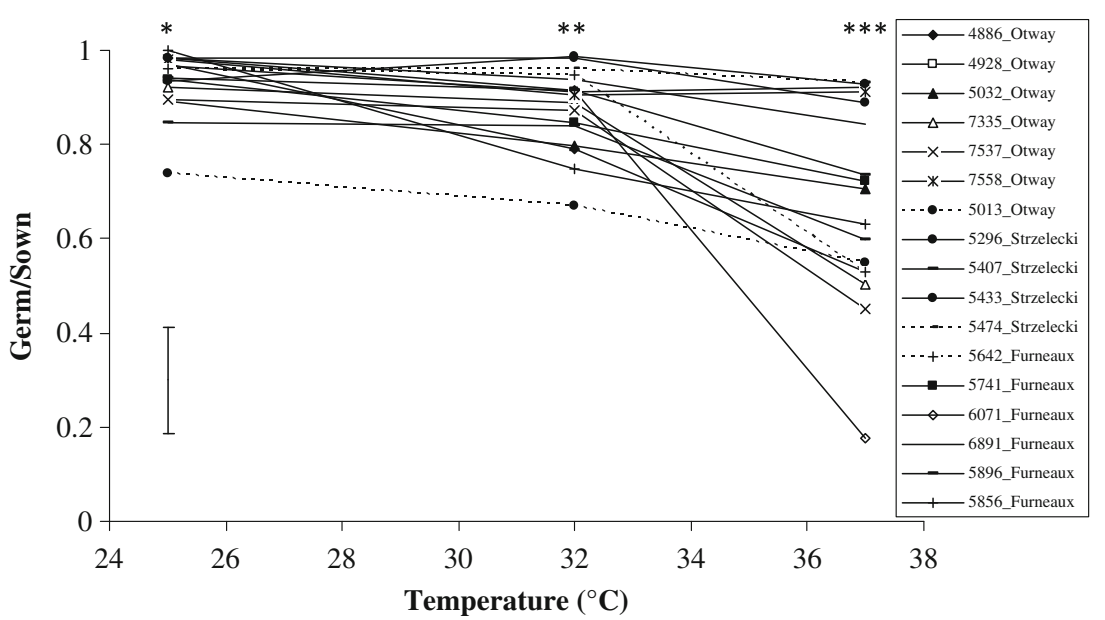

Fig. 1 Least-square means for the germination proportion (Germ/Sown) from E. globulus seeds collected from 17 genotypes growing in a seed orchard in Tasmania, sampled in 2007/08. The bar indicates twice the average standard error. Significance of the fixed genotype effect tested separately at each temperature is indicated ( $n s$ not significant; $* P<0.05$, $* * P<0.01, * * * P<0.001)$. The significant interaction between genotype and temperature was mainly due to several genotypes, particularly 6071 , exhibiting an adverse germination response at $37^{\circ} \mathrm{C}$ 
a) $2007 / 08$

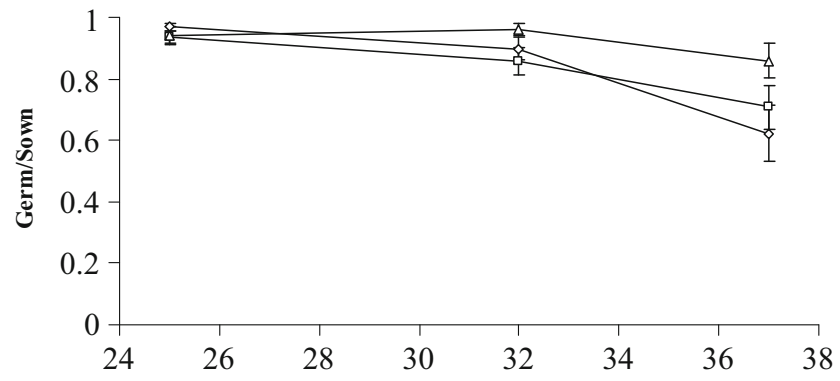

b) $2008 / 09$

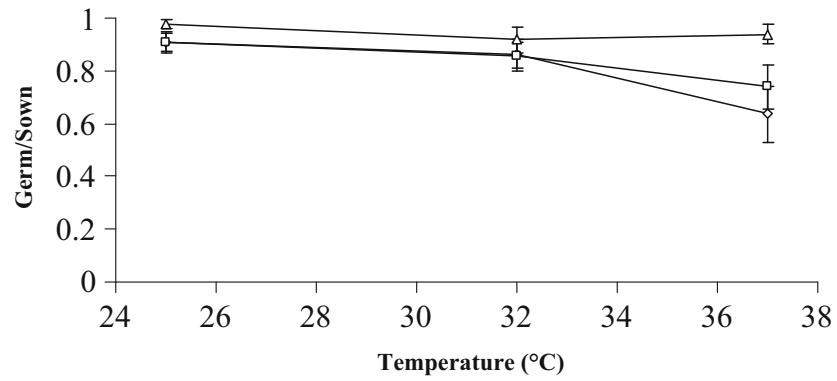

Fig. 2 Least-square means $( \pm$ s.e.) for the germination proportion (Germ/Sown) from E. globulus seeds collected from genotypes from three races (diamond Furneaux, square Otway, triangle Strzelecki) growing in a seed orchard in Tasmania and sampled in a 2007/08 ( $n$ genotypes $=17)$ and b 2008/09 ( $n$ genotypes $=16)$ seasons. The seeds were germinated at three temperatures $\left(25,32\right.$ and $\left.37^{\circ} \mathrm{C}\right)$. While the race effect was not significant, the race by temperature interaction was significant at $P=0.041$ in $2007 / 08$ and at $P=0.113$ in $2008 / 09$

was significant in 2008/09 (Table 1). However, in each season, the race $\times$ temperature interaction was not significant at the $P=$ 0.05 level (Table 1). High temperatures increased the proportion of germinated seed that became diseased $\left(2008 / 09 F_{2,25}=\right.$ 5.7, $P=0.009)$, developed stunted radicles $\left(2007 / 08 F_{2,27}=\right.$ 10.3, $\left.P<0.001 ; 2008 / 09 F_{2,26}=16.2, P<0.001\right)$ and failed to shed the seed coat $\left(2007 / 08 F_{2,27}=24.6, P<0.001 ; 2008 / 09\right.$ $\left.F_{2,26}=65.8, P<0.001\right)$. However, the insignificant race $\times$ temperature interactions for all of these abnormalities indicated that developing seedlings of the different races were similarly adversely affected by high temperatures.

Genetic differences in rate traits occurred both between and within races, but these differences were generally insensitive to variation in the test temperatures (Table 1). These race differences were mainly due to the Strzelecki seed lots having faster germination and faster normal seedling development across all temperatures (Fig. 3). The temperature $\times$ race interaction was only significant in one case $(2007 / 08$ T50Normals $P<0.05$; Table 1$)$ due to the differences amongst races being insignificant at $25^{\circ} \mathrm{C}$ $\left(F_{2,28}=1.8, P=0.187\right)$, but significant at high temperatures $\left(32{ }^{\circ} \mathrm{C} F_{2,28}=6.0, P=0.007 ; 37{ }^{\circ} \mathrm{C} F_{2,28}=4.8, P=0.016\right)$. This difference was due to the Strzelecki seed lots being least delayed by increasing test temperature (Fig. 3), a a) $2007 / 08$

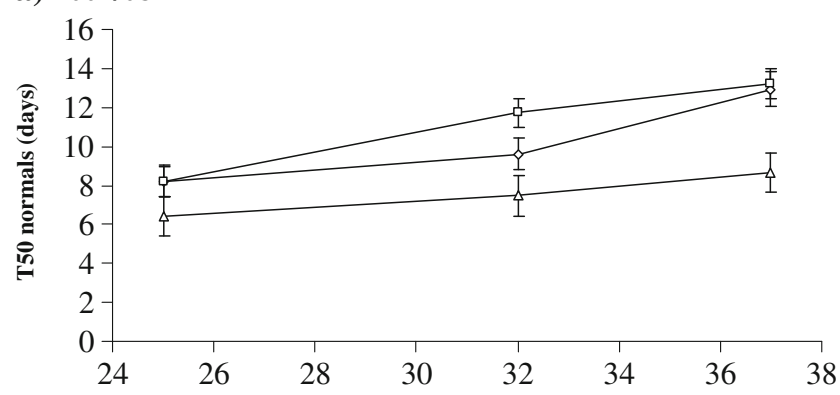

b) $2008 / 09$

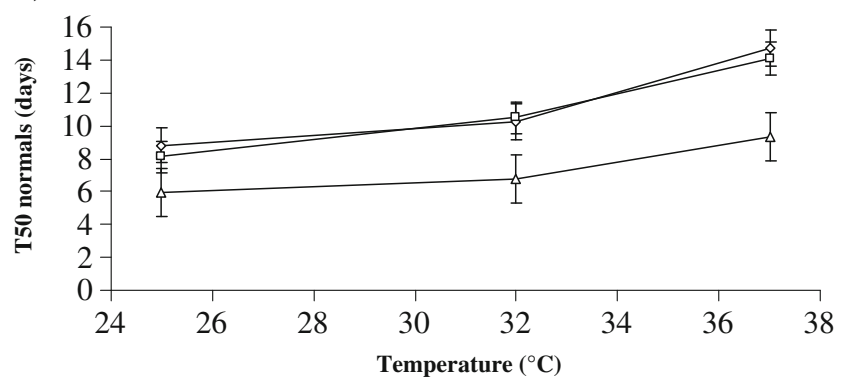

Fig. 3 Least-square means ( \pm s.e.) for the rate (T50) of normal seedling development (days) from E. globulus seeds collected from three races (diamond Furneaux, square Otway, triangle Strzelecki) growing in a seed orchard in Tasmania and sampled in a 2007/08 ( $n$ genotypes $=17)$ and $\mathbf{b} 2008 / 09$ ( $n$ genotypes $=16$ ) seasons. The seeds were germinated at three temperatures $\left(25,32\right.$ and $\left.37{ }^{\circ} \mathrm{C}\right)$. The race effect was significant at $P=0.034$ in $2007 / 08$ and at $P=0.051$ in $2008 / 09$

trend evident in both seasons and for both germination rate and rate of normal seedling development.

\subsection{Stability of genotype effects across seasons}

Neither season nor its interaction terms with race or genotype affected the rate traits, indicating stable genetic control of developmental rate. However, the genotype, genotype by season and the three-way interaction with temperature were usually significant for both the germination proportion (Germ/Sown - genotype $F_{13,25}=4.8, P<0.001$; season $\times$ genotype $F_{13,25}=2.5, P=0.025$; season $\times$ genotype $\times$ temperature $\left.F_{26,45}=3.5, P=<0.001\right)$ and the proportion of germinated seeds that developed into normal seedlings (Normals/Germ - genotype $F_{13,25}=2.3, P=0.038$; genotype $\times$ season $F_{13,25}=1.7, P=$ 0.137 ; genotype $\times$ season $\times$ temperature $F_{25,43}=4.2, P=<0.001$ ). While these genotype interactions could not be explained by significant interactions at the race level with this smaller data set $(P>0.1)$, the trend for the germination proportion of the Strzelecki seed lots to be least adversely affected by the $37{ }^{\circ} \mathrm{C}$ treatment was evident across seasons (data not shown). There was a highly significant three-way interaction for both proportion traits, but this was mainly due to the degree to which the high temperature adversely impacted genotypes in the different seasons. Seed lots from 6 of the 14 genotypes were more adversely affected by high temperature in 2007/08 than 
Table 2 Effect of E. globulus genotype and season on seed weight and the number of seeds per capsule

\begin{tabular}{|c|c|c|c|c|c|c|}
\hline \multirow[b]{2}{*}{ Fixed effects } & \multirow[b]{2}{*}{ Num d. f. } & \multirow[b]{2}{*}{ Den d. f. } & \multicolumn{2}{|c|}{ Seed weight } & \multicolumn{2}{|c|}{$\begin{array}{l}\text { Seeds per } \\
\text { capsule }\end{array}$} \\
\hline & & & $F$ & $P$ & $F$ & $P$ \\
\hline Season & 1 & 52 & 32.8 & $<0.001$ & 6.2 & 0.016 \\
\hline Genotype & 13 & 52 & 22.4 & $<0.001$ & 3.3 & 0.001 \\
\hline Season $\times$ genotype & 13 & 52 & 2.2 & 0.024 & 2.2 & 0.022 \\
\hline
\end{tabular}

The data were derived from seeds collected in 2007/08 and 2008/09 from the 14 genotypes which were sampled in both seasons. Genotypes were represented by multiple ramets

$2008 / 09$, but only one was more adversely affected in 2008/09. Nevertheless, in this seasonal data set, there were subsets of genotypes where, for example, in both seasons the germination proportion was not significantly affected by high temperature (genotypes 4928, 5032, 5741, 6891 in Fig. 1) as well as others which were consistently adversely affected (e.g. 5642 and 6071; $P<0.001$ in both seasons).

\subsection{Effect of seed set and seed size}

There was a significant effect of genotype and season on the number of seeds per capsule and seed weight (Table 2). The seasonal effect was due to fewer and heavier seeds being obtained in 2007/08 (seeds per capsule was 7.5 \pm 1.4 and seed weight was $0.23 \pm 0.01 \mathrm{~g} / 100$ seeds) than in 2008/09 (seeds per capsule was $10.6 \pm 1.4$ and seed weight was $0.20 \pm 0.01$ $\mathrm{g} / 100$ seeds), although these effects varied slightly with genotype for both traits. The race differences for either trait were not significant (seeds per capsule $F_{2,11}=2.0, P=0.189$; seed weight $F_{2,11}=2.7, P=0.110$ ), although there was a trend for Strzelecki to have smaller seeds than Otways and Furneaux.

When included as a covariate in the mixed model analyses across seasons, the number of seeds per capsule did not significantly affect any response trait. While seed weight did not affect the proportion traits, increased seed weight did result in faster germination (T50Germ $F_{1,44}=$ 5.8, $P=0.020)$ and faster normal seedling development (T50Normals $F_{1,44}=6.1, P=0.018$ ). The inclusion of seed weight did not diminish the significance of any of the genetic effects or their temperature interactions in the across or within season analyses. Rather in several cases, the genetic effect on rate traits increased in significance (2008/2009 race effect T50Germ $F_{1,13}=4.1, P=0.043$ and T50Normals $F_{1,13}=4.5, P=0.033$ ). It should be noted that the season term in the mixed models includes differences in season, germination test experiments (but controls were used to adjust for gross differences), seed development time and pollination type. When pollination type (OP or
MSP) was tested in the 2008/09 season (when it was most variable), no significant effect $(P>0.05)$ was detected on any trait, arguing that the increased number of MSP seed lots sampled in the 2008/09 season is unlikely to account for the observed season by genotype interactions.

\section{Discussion}

Our replication and randomisation of maternal genotypes in a common environment clearly shows a genetic basis to intraspecific variation in seed germination traits in E. globulus. Previous studies of eucalypts have reported differences in germination characteristics of seeds sourced from different geographic origins (Battaglia 1997; Humara et al. 2000; López et al. 2003). However, these studies confound differences in maternal environment and genetics. For example, significant differences in dormancy/non-dormancy cycles were detected amongst populations of the Australian accessions of the annual Emex australia from wild collected seed (Panetta and Randall 1993). However, these differences were not evident when maternal genotypes were grown in a common environment, arguing for a maternal environmental rather than maternal genetic effect.

In the present study, a component of the genetic variation in both proportion and rate traits could be attributed to the race of origin. There were differences amongst races in the rate of normal seedling development due to Strzelecki having significantly faster seedling development than both the Otway and Furneaux races. Seed size and the number of seeds per capsule are under genetic control in E. globulus (McGowen et al. 2004a). A significant negative genetic correlation has been shown between the number of seeds per capsule and seed size such that selection for a large number of seeds per capsule would result in reduced seed size (McGowen et al. 2004a). Strzelecki has been reported to have smaller capsules and smaller seeds than the Otway and Furneaux races (McGowen et al. 2004a). While a similar trend in seed weight was detected in the present study, the race differences were not significant. López et al. (2003) found that E. globulus seed mass exhibited a significant maternal effect, increasing seed germinative capacity but not germination rate. In other E. globulus studies, the rate of germination increased with increasing seed size (López et al. 2000), consistent with the trends observed for seed weight in the present study.

When seed weight was included in analyses of the germination traits, strong differences between genotypes remained, including the observed differences between races. Indeed, the trend for heavier E. globulus seeds to germinate faster is contrary to the racial differences in these traits. This was due to seeds from the Strzelecki race having the fastest germination and seedling development rate but also being smaller than 
those seeds from the Otway and Furneaux races which had slower rates of germination and seedling development. The opposite would have been expected, based on the published reports of increased seed size being correlated with increased germination rate (López et al. 2000). This argues that the race differences in seed germination traits observed are not due to genetic differences in seed weight/maternal provisioning, and thus have a more complex underlying mechanism (Bischoff et al. 2006; Cendan et al. 2013). Indeed, the complexity of the genetic effects on germination is exemplified by the differential response of seed lots from different genotypes to temperature in the proportion traits but little difference observed for rate traits, which suggests multiple mechanisms may underlie the observed genetic differences.

It is unknown whether the genetic differences in the degree to which high temperature stress reduces germination proportion is due to a differential threshold for entering secondary dormancy or mortality of the embryo. There is evidence in other species that high temperature exposure during germination can induce thermoinhibition or thermodormancy. The failure of seeds to germinate at high temperature is termed thermoinhibition when germination proceeds immediately when the temperature is reduced below a certain threshold, or thermodormancy if some form of dormancy-breaking treatment is required before germination can proceed at the favourable temperature (Corbineau et al. 2002; Kepczynski and Bihun 2002; Hills and van Staden 2003). It is possible that the racial differences observed result from different thresholds for the induction of thermodormancy. However, while the majority of ungerminated seeds at high temperature appeared on squashing to have healthy and intact embryos, it is possible that the high temperature exposure would have induced physiological changes in the seed which may have rendered them non-viable. High temperature exposure during germination has been shown to cause damage to metabolic functions such as protein denaturation, reduced enzyme function, membrane damage, alteration of energy metabolism, DNA synthesis and leakage of electrolytes and potassium (Bewley and Black 1994; Corbineau et al. 2002; Taylor et al. 2007).

The E. globulus from the Strzelecki Ranges is genetically differentiated from the more coastal populations in the Otway Ranges and islands of the Furneaux group (Jones et al. 2013) and is the most drought tolerant of the E. globulus races (Strzelecki $>$ Furneaux $>$ Western Otways; (Dutkowski and Potts 2012)). The ranking of the races in terms of their tolerance to germination at high temperatures (Strzelecki $>$ Western Otways $>$ Furneaux; Fig. 1) matches the home-site ranking for the mean maximum temperature of the warmest month which were $24.2,22.3$ and $21.4{ }^{\circ} \mathrm{C}$, respectively. It is thus possible that the genetic differences in germination response, including the rapid germination and seedling development as well as the greater ability of the Strzelecki genotypes to germinate under high temperatures, are signals of adaptation to more drought prone, high temperature environments. Such early life adaptations have been reported in other plant species (GiménezBenavides et al. 2007; Donohue et al. 2010), including early or rapid germination to avoid drought stress (Allen and Meyer 1998; Verslues and Juenger 2011). In eucalypts, while the stratification requirements of higher altitude provenances of many species are well-known from native forest seed collections (Close and Wilson 2002), adaptation of species germination traits to drought and high temperatures has been poorly studied.

The race differences in germination proportion were only manifest at high temperatures, and were due to the higher tolerance of the Strzelecki genotypes. The influence of the maternal genotype on germination traits could have been due to the maternal contribution to the nucleus of the embryo (one half maternal), or true maternal effects arising from the maternally derived seed coat, maternal plastid inheritance (McKinnon et al. 2001), or maternal provisioning of the seeds (Roach and Wulff 1987; Donohue 2009; Bischoff and MullerScharer 2010). In the present study, the crossing design does not allow the cause of the maternal genotype influence on seed germination traits to be determined. However, in a study of reciprocal crosses of E. globulus, Rix et al. (2012b) showed that both the male and female genotype may affect various aspects of seed germination and early seedling development, independent of seed size, but the response to high temperature stress was more influenced by the maternal than paternal parent.

While there are race differences in germination response and early seedling growth which appear independent of maternal seed provisioning, we cannot completely dismiss the possibility that the observed differences are not due to epigenetic changes (Bräutigam et al. 2013). Such changes can be induced by environmental stress (Zhang et al. 2013) and result in phenotypic effects that are adaptive (Bräutigam et al. 2013; Jablonka 2013). For example, exposure to heat stress has been shown to cause intragenerational epigenetic changes in cork oak (Correia et al. 2013), and transgenerational molecular and phenotypic changes in Arabidopsis (Boyko and Kovalchuk 2010; Suter and Widmer 2013). However, while there are exceptions (Grossniklaus et al. 2013), the transgenerational epigenetic memory is often relatively transient and only detected in the direct progeny produced following maternal environmental conditioning (Boyko and Kovalchuk 2010; Grossniklaus et al. 2013; Holeski et al. 2013; Migicovsky and Kovalchuk 2013; Suter and Widmer 2013).

It is unlikely that environmentally induced epigenetic memory from the native home-site is a cause of our race differences. This would require epialleles to be stably inherited across one or two generations, depending upon whether the signal is a result of the exposure of the native open-pollinated tree (grandparent of our seed lots) or the seeds developing on these trees, 
respectively. In addition, the intrageneration memory would also need to persist over more than 18 years and across six opportunities for maternal epigenetic reset ( $\mathrm{Tal}$ et al. 2010; Raj et al. 2011). These reset opportunities include growth of the parental genotypes in (i) different seedling nurseries in Western Australia, (ii) different base population field trials in Western Australia for 5-6 years (Costa e Silva et al. 2006), (iii) grafting of scions and subsequent nursery growth (c. 1 year), (iv) planting in an arboretum in Western Australia (2-4 years), (v) re-grafting and nursery growth in Tasmania (7-12 months) and (vi) planting in Tasmania in the common environment seed orchard studied (5-6 years) (Potts et al. 2008).

While race differences tend to be maintained across seasons, at the genotype level there was evidence for significant three-way interactions due to $43 \%$ of seed lots exhibiting greater temperature sensitivity in 2007/08 than 2008/09 for germination proportion and the proportion of germinated seeds that developed into normal seedlings. This could be due to many factors including (i) subtle differences in the test conditions, (ii) seasonally induced differences, (iii) differences in pollination environment and (iv) differences in seed maturation. It is unlikely differences in seed maturity at harvest is contributing to genotype differences in the proportion traits as previous studies argue that harvest time affects rate, rather than proportion traits (Rix et al. 2012a). Despite a report of seasonal stability in outcrossing rates in E. globulus (McGowen et al. 2004b), the possibility that this interaction is due to differences in outcrossing rates between seasons cannot be dismissed. For example, a study of five ramets of a single genotype showed that selfed seeds exhibited a greater sensitivity to high temperatures than outcrossed seeds for the proportion of germinated seeds that developed into normal seedlings (K. Rix unpubl. data). Another possible reason for the observed seasonal differences in the response to high temperature stress is that it arises from a true plastic, physiological effect arising from some genotypes experiencing differences in the maternal environment between seasons (see epigenetic discussion above; Cendan et al. (2013)). For example, Sung et al. (1998) showed that the upper temperature limit for germination of lettuce seeds could be modified by manipulating the temperature of the maternal environment during seed production, with seeds developing under higher temperature conditions having increased tolerance to high temperature stress. This does not appear to be a cause of seasonal variation in the present case as there was little difference in the frequency of high temperatures during seed development, if anything the season where seed was more sensitive to high temperature stress (2008-2009) was slightly hotter (2007-2008 had 9 days over $30^{\circ} \mathrm{C}$ and an average maximum temperature of $18.3^{\circ} \mathrm{C}$ versus 13 days and $18.4{ }^{\circ} \mathrm{C}$ in 2008-2009, Bureau of Meteorology data for the nearby Hobart airport; Jones et al. (2011)).

In conclusion, the genetic differences we observed in germination proportion were most manifest at high temperatures, a finding which has several practical implications for commercial nurseries subject to such conditions. Firstly, when bulk seed lots are germinated, the discrepancy between genotype frequencies in the sown seed and seedling populations will be greater than expected under optimal temperatures. Secondly, there will be a higher cost to production of seedlings from high temperature-sensitive seed lots due to reduced seed germination and seedling development. Thirdly, variation in rates of seed germination or development will increase the heterogeneity in seedling size, resulting in additional sorting being required to provide batches of seedlings which meet size specifications. As seed lots are differentiated on other facets of the germination response than germination proportion alone, it would be more useful for commercial germination tests to also measure proportion normal seedling development as well as rate traits, as germination alone does not guarantee seedling development. While the causative mechanisms underlying the genetic differences observed are unknown, the present study clearly shows the complexities of the germination response and highlights the need for seed lot-specific germination testing as tree genetics, season and maternal environment vary.

Acknowledgments We thank Jessica Rix, Marek Matuszek, Shaun Suitor and Richard Holmes for their assistance, as well as David Pilbeam of the Southern Tree Breeding Association for organising collection of seed from the Manjimup seed orchard.

Funding This work was supported by seedEnergy Pty Ltd and a Tasmanian Graduate Research Scholarship to K. Rix.

\section{References}

Allen PS, Meyer SE (1998) Ecological aspects of seed dormancy loss. Seed Sci Res 8:183-192

Andersson B (1994) Aftereffects of maternal environment on autumn frost hardiness in Pinus sylvestris seedlings in relation to cultivation techniques. Tree Physiol 14:313-322

Battaglia M (1997) Seed germination model for Eucalytpus delegatensis provenances germinating under conditions of variable temperature and water potential. Aust J Plant Physiol 24:69-79

Bekendam J, Grob R (1993) Handbook for seedling evaluation. ISTA Association, Zurixh

Besnard G, Achere V, Jeandroz S, Johnsen O, Rampant PF, Baumann R, Mueller-Starck G, Skroppa T, Favre JM (2008) Does maternal environmental condition during reproductive development induce genotypic selection in Picea abies? Ann. For. Sci. 65, Article 109 DOI: 10.1051/forest:2007081

Bewley JD, Black M (1994) Seeds: physiology of development and germination. Plenum Press, New York

Bischoff A, Muller-Scharer H (2010) Testing population differentiation in plant species - how important are environmental maternal effects. Oikos 119:445-454

Bischoff A, Vonlanthen B, Steinger T, Mueller-Schaerer H (2006) Seed provenance matters - effects on germination of four plant species used for ecological restoration. Basic Appl Ecol 7:347-359

Boyko A, Kovalchuk I (2010) Transgenerational response to stress in Arabidopsis thaliana. Plant Signal Behav 5:995-8

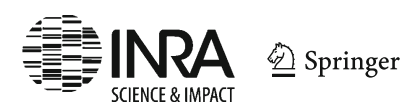


Bräutigam K, Vining KJ, Lafon-Placette C, Fossdal CG, Mirouze M, Gutierrez Marcos J, Fluch S, Fernandez Fraga M, Angeles Guevara M, Abarca D, Johnsen Ø, Maury S, Strauss SH, Campbell MM, Rohde A, Diaz-Sala C, Cervera MT (2013) Epigenetic regulation of adaptive responses of forest tree species to the environment. Ecol Evol 3:399-415

Byers DL, Platenkamp GAJ, Shaw RG (1997) Variation in seed characters in Nemophila menziesii- evidence of a genetic basis for maternal effect. Evolution 51:1445-1456

Cendan C, Sampedro L, Zas R (2013) The maternal environment determines the timing of germination in Pinus pinaster. Environ Exp Bot 94:66-72

Close DC, Wilson SJ (2002) Provenance effects on pre-germination treatments for Eucalyptus regnans and E. delegatensis seed. For Ecol Manage 170:299-305

Corbineau F, Gay-Mathieu C, Vinel D, Come D (2002) Decrease in sunflower (Helianthus annuus) seed viability caused by high temperature as related to energy metabolism, membrane damage and lipid composition. Physiol Plant 116:489-496

Correia B, Valledor L, Meijon M, Rodriguez JL, Dias MC, Santos C, Canal MJ, Rodriguez R, Pinto G (2013) Is the interplay between epigenetic markers related to the acclimation of Cork Oak plants to high temperatures? PLoS One 8:e53543

Costa e Silva J, Potts BM, Dutkowski G (2006) Genotype by environment interaction for growth of Eucalyptus globulus in Australia. Tree Genet Genome 2:61-75

Donohue K (2009) Completing the cycle: maternal effects as the missing link in plant life histories. Philos Trans R Soc Lond B Biol Sci 364: 1059-1074

Donohue K, Rubio De Casas R, Burghardt L, Kovach K, Willis CG (2010) Germination, postgermination adaptation, and species ecological ranges. Annu Rev Ecol Evol Syst 41:293-319

Dutkowski GW, Potts BM (1999) Geographic patterns of genetic variation in Eucalyptus globulus ssp globulus and a revised racial classification. Aust J Bot 47:237-263

Dutkowski GW, Potts BM (2012) Genetic variation in the susceptibility of Eucalyptus globulus to drought damage. Tree Genet Genome 8: $757-773$

Galloway LF (2001) The effect of maternal and paternal environments on seed characters in the herbaceous plant Campanula americana (Campanulaceae). Am J Bot 88:832-840

Galloway LF, Etterson JR, McGlothlin JW (2009) Contribution of direct and maternal genetic effects to life-history evolution. New Phytol 183:826-838

Giménez-Benavides L, Escudero A, Iriondo JM (2007) Local adaptation enhances seedling recruitment along an altitudinal gradient in a high mountain Mediterranean plant. Ann Bot 99:723-734

Grossniklaus U, Kelly B, Ferguson-Smith AC, Pembrey M, Lindquist S (2013) Transgenerational epigenetic inheritance: how important is it? Nat Rev Genet 14:228-235

Hills PN, van Staden J (2003) Thermoinhibition of seed germination. S Afr J Bot 69:455-461

Holeski LM, Zinkgraf MS, Couture JJ, Whitham TG, Lindroth RL (2013) Transgenerational effects of herbivory in a group of long-lived tree species: maternal damage reduces offspring allocation to resistance traits, but not growth. J Ecol 101:1062-1073

Humara JM, Lopez M, Casares A, Majada J (2000) Temperature and provenance as two factors affecting Eucalyptus nitens seed germination. For 73:87-90

SAS Institute Inc (2003) SAS 9.1 for Windows. In. Ed. S Institute. SAS Institute: Cary, NC, USA

ISTA (2006) ISTA Handbook on Seedling Evaluation

ISTA (2012) International Rules for Seed Testing. Seed Sci Technol 40

Jablonka E (2013) Epigenetic inheritance and plasticity: the responsive germline. Prog Biophys Mol Biol 111:99-107
Jones TH, Steane DA, Jones RC, Pilbeam D, Vaillancourt RE, Potts BM (2006) Effects of domestication on genetic diversity in Eucalyptus globulus. For Ecol Manage 234:78-84

Jones RC, Vaillancourt RE, Gore PL, Potts BM (2011) Genetic control of flowering time in Eucalyptus globulus ssp globulus. Tree Genet Genome 7:1209-1218

Jones RC, Steane DA, Lavery M, Vaillancourt RE, Potts BM (2013) Multiple evolutionary processes drive the patterns of genetic differentiation in a forest tree species complex. Ecol Evol 3:1-17

Kepczynski J, Bihun M (2002) Induction of secondary dormancy in Amaranthus caudatus seeds. Plant Growth Regul 38:135-140

Lacey EP (1998) What is an adaptive environmentally induced parental effect? In: Mousseau T, Fox C (eds) Maternal effects as adaptations. Oxford University Press, New York, pp 54-66

López M, Humara JM, Casares A, Majada J (2000) The effect of temperature and water stress on laboratory germination of Eucalyptus globulus Labill. seeds of different sizes. Ann For Sci 57:245-250

López GA, Potts BM, Vaillancourt RE, Apiolaza LA (2003) Maternal and carryover effects on early growth of Eucalyptus globulus. Can J For Res 33:2108-2115

Mazer SJ, Gorchov DL (1996) Paternal effects on progeny phenotype in plants - distinguishing genetic and environmental causes. Evolution 50:44-53

McGowen MH, Potts BM, Vaillancourt RE, Gore PL, Williams DR (2004a) The genetic control of sexual reproduction in Eucalyptus globulus. In: Eds NMG B, Pereira JS, Marques C, Coutinho J, Madeira M, Tomé M (eds) Eucalyptus in a changing world. Instituto Investigação de Floresta e Pape, Aveiro, pp 104-108

McGowen MH, Williams DR, Potts BM, Vaillancourt RE (2004b) Stability of outcrossing rates in Eucalyptus globulus seedlots. Silvae Genet 53:42-44

McKinnon GE, Vaillancourt RE, Tilyard PA, Potts BM (2001) Maternal inheritance of the chloroplast genome in Eucalyptus globulus and interspecific hybrids. Genome 44:831-835

Migicovsky Z, Kovalchuk I (2013) Changes to DNA methylation and homologous recombination frequency in the progeny of stressed plants. Biochem Cell Biol 91:1-5

Monty A, Lebeau J, Meerts P, Mahy G (2009) An explicit test for the contribution of environmental maternal effects to rapid clinal differentiation in an invasive plant. J Evol Biol 22:917-926

Panetta FD, Randall RP (1993) Variation between Emex australis populations in seed dormancy/non-dormancy cycles. Aust J Ecol 18: 275-280

Patterson B, Gore P, Potts BM, Vaillancourt RE (2004) Advances in pollination techniques for large-scale seed production in Eucalyptus globulus. Aust J Bot 52:781-788

Potts BM, McGowen MH, Williams DR, Suitor S, Jones TH, Gore PL, Vaillancourt RE (2008) Advances in reproductive biology and seed production systems of Eucalyptus: the case of Eucalyptus globulus. South For 70:145-154

Raj S, Braeutigam K, Hamanishi ET, Wilkins O, Thomas BR, Schroeder W, Mansfield SD, Plant AL, Campbell MM (2011) Clone history shapes Populus drought responses. Proc Natl Acad Sci U S A 108: 12521-12526

Rasanen K, Kruuk LEB (2007) Maternal effects and evolution at ecological time-scales. Funct Ecol 21:408-421

Rix KD, Gracie AJ, Potts BM, Brown PH, Spurr CJ, Gore PL (2011) Germination response of Eucalyptus globulus seeds exposed to low and high temperature stress. Seed Sci Technol 39:686-691

Rix KD, Gracie AJ, Potts BM, Brown PH, Spurr CJ, Gore PL (2012a) The effect of time of harvest, irrigation treatments and kilning temperature on Eucalyptus globulus seed germination response to high temperature stress. Seed Sci Technol 40:185-199 
Rix KD, Gracie AJ, Potts BM, Brown PH, Spurr CJ, Gore PL (2012b) Paternal and maternal effects on the response of seed germination to high temperatures in Eucalyptus globulus. Ann For Sci 69:673-679

Roach DA, Wulff RD (1987) Maternal effects in plants. Annu Rev Ecol Syst 18:209-235

Stackpole DJ, Vaillancourt RE, Alves A, Rodrigues J, Potts BM (2011) Genetic variation in the chemical components of Eucalyptus globulus wood. G3-Genes Genom. Genet 1:151-159

Stoehr MU, L'Hirondelle SL, Binder WD, Webber JE (1998) Parental environment aftereffects on germination, growth, and adaptive traits in selected white spruce families. Can J For Res 28:418-426

Suitor S, Potts BM, Brown PH, Gracie AJ, Gore PL (2008) Postpollination capsule development in Eucalyptus globulus seed orchards. Aust J Bot 56:51-58

Sung Y, Cantliffe DJ, Nagata RT (1998) Seed developmental temperature regulation of thermotolerance in lettuce. J Am Soc Hortic Sci 123: 700-705
Suter L, Widmer A (2013) Environmental heat and salt stress induce transgenerational phenotypic changes in Arabidopsis thaliana. PLoS One 8

Tal O, Kisdi E, Jablonka E (2010) Epigenetic contribution to covariance between relatives. Genetics 184:1037-1050

Taylor NJ, Hills PN, van Staden J (2007) Cell division versus cell elongation: the control of radicle elongation during thermoinhibition of Tagetes minuta achenes. J Plant Physiol 164:1612-1625

Verslues PE, Juenger TE (2011) Drought, metabolites, and Arabidopsis natural variation: a promising combination for understanding adaptation to water-limited environments. Curr Opin Plant Biol 14:240-245

Xu T, Hutchinson M (2010) ANUCLIM Version 6.1 User Guide. Centre for Resource and Environmental Studies, Australian National University

Zhang Y-Y, Fischer M, Colot V, Bossdorf O (2013) Epigenetic variation creates potential for evolution of plant phenotypic plasticity. New Phytol 197:314-322 